\title{
Literatur
}

1. WAkIL, S. J., J. Lipid Res. 2, 1 (1961). -2. HARLAN jr., W.R. und S. J. Wakit, J. biol. Chemistry 238, 3216 (1963). - 3. Brady, R. O. und S. Gurin, J. biol. Chemistry 199, 421 (1952). - 4. Diruri, F. und S. Gurin, Arch. Biochem. Biophysics 43, 231 (1953). - 5. Van Banlen, J. und S. Gurin, J. biol. Chemistry 205, 303 (1953). - 6. MAsoro, E. J., J. Lpid Res. 3, 149 (1962). 7. Numa, S., M. Matsuriashi und F. Lynen, Biochem. Z. 334, 203 (1961). - 8. Seitz, W. und V. von Brand, Zschr. inn. Med., Leipzig 13, 764 (1958). - 9. Seitz, W. und V. von Brand, Klin. Wschr. 39, 891 (1961). - 10. von Brand, V., Biochem. Z. 331, 162 (1959). - 11. von Brand, V. und W. SeItz, Med. Klinik 55, 723 (1960). - 12. von Brand, V. und W. Sertz, Klin. Wschr. 36, 587 (1958). - 13. NAgengast-von Brand, V. und W. Seit', Klin. Wschr. 43, 402 (1965). - 14. von Brand, V. und E. Helmreici, Biochem. Z. 328, 146 (1956). - 15. Hannig, K. Z. analyt. Chem. 181, 244 (1961). - 16. Weichselbaum, T. E., Amer. J. Clin. Path. 10, 49 (1946). - 17. BArtlett, G. R., J. biol. Chemistry 234, 466 (1959). - 18. Discre, Z., in: D. Glick, Methods of Biochemical
Analysis. Bd. 2, S. 320. Interscience Publ., New York-London 1955. - 19. Grassmann, W. und K. Hannig, Klin. Wschr. 32, 838 (1954). - 20. Ouchterlony, O., Progr. Allergy 6, 30 (1962). - 21. Brady, R. O., R. M. Bradefy und E. G. Trams, J. biol. Chemistry 23.5, 3093 (1960). - 22. Tietz, A., Biochem. biophysica Acta (Amsterdam) 25, 303 (1957). - 23. Martin, D. B., M. G. Horning und P. R. Vagelos, J. biol. Chemistry 236, 663 (1961). - 24. Brady, R. O., A.-M. Mamoon und E. R. Stadtalan, J. biol. Chemistry 222, 795 (1956). - 25. BRADY, R. O., J. biol. Chemistry 235, 3099 (1960). - 26. Brady, R. O., E. G. Trams und R. M. Bradley, Biochem. biophysic Res. Commun. 2, 256 (1960). 27. Bressler, R. und S. J. Wakil, J. biol. Chemistry 237, 1441 (1962). - 28. Shaw, W. N., F. Dituri und S. Gurin, J. biol. Chemistry 226, 417 (1957). - 29. Auraham, S., K. J. Matthes und I. L: Charkoff, J. biol. Chemistry 235, 2251 (1960). - 30. Matthes, K. J., S. Abraham und I. L. Cilaikoff, J. biol. Chemistry $235,2560(1960)$.

\section{Semiquantitative, dünnschichtchromatographische Bestimmung der Gallensäuren im Serum, Duodenalsaft und Stuhl}

\author{
Von H.-Ch. Curtrus \\ Aus dem Mediqinisch-cbemischen Laboratorium der Universitäts-Kinderklinik Zïrich (Direktor: Prof. Dr. A. Prader) ${ }^{1}$ )
}

(Eingegangen am 4. Mai 1965)

\begin{abstract}
Es wird eine dünnschichtchromatographische Methode für die semiquantitative Bestimmung der Gallensäuren und deren Konjugate bei gesunden Erwachsenen beschrieben. Die Methode kann auch für die Bestimmung der Gallensäuren im Duodenalsaft und im Stuhl verwendet werden.

A thin layer chromatographic method is described for the semiquantitative determination of bile acids and their conjugates in healthy adults. The method can also be used for the determination of bile acids in duodenal juice and faeces.
\end{abstract}

Im menschlichen Serum sind bis jetzt Cholsäure, Desoxycholsäure und Chenodesoxycholsäure nachgewiesen und quantitativ bestimmt worden. Diese drei Gallensäuren kommen in freier wie auch in konjugierter Form vor. Bei den Konjugaten besteht eine Peptidbindung zwischen der Carboxylgruppe der Gallensäure einerseits und der Aminogruppe von Taurin bzw. Glycin andererseits.

Für die quantitative Bestimmung müssen die Gallensäuren aus dem Serum von den Eiweißen getrennt und isoliert werden. Die am häufigsten verwendete Methode besteht in der Fällung der Eiweiße mit äthanolischer Bariumhydroxyd-Lösung, die mit Bariumacetat gesättigt ist, nach JosephsoN (1). Aus dem Uberstand werden die Lipide mit Essigester extrahiert. Die Gallensäuren bleiben, weil sie als Bariumsalze vorliegen, in der wässerigen Phase zurück und können mit Furfurol/Schwefelsäure in einen Farbkomplex überführt und photometrisch bestimmt werden. - Bessere Resultate werden erzielt, wenn die Gallensäuren nach der Extraktion photometrisch im UV-Bereich (2) bei $350 \mathrm{~m} \mu$ oder fluori-

1) Der größte Teil der experimentellen Arbeiten wurde im Med.Chem. Zentrallaboratorium des Kantonsspitals Zürich (Leiter: P. D. Dr. H. RosenMund) ausgeführt. metrisch (3) bei $490 \mathrm{~m} \mu$ gemessen werden. Da sich die Absorptionsspektren von Desoxycholsäure und Chenodesoxycholsäure in Äthylacetat, Schwefelsäure, Essigsäureanhydrid und Salicylaldehyd-Schwefelsäure-Eisessig voneinander unterscheiden, können auch - mit gewissem Vorbehalt - Aussagen über die quantitative Verteilung der beiden Einzelkomponenten gemacht werden.

Die Extraktionsmethode nach Josephson weist verschiedene Nachteile auf. Die im Vergleich zu den Gallensäuren in viel größerer Menge vorhandenen Lipide, wie Cholesterin, Phosphatide und Monoglyceride werden nicht quantitativ entfernt und stören die nachfolgende Bestimmung. Dasselbe gilt für andere Extraktionsverfahren $(4,5)$. Außerdem entsteht gerade durch die Extraktion ein nicht zu vernachläßigender Verlust vor allem an freien Gallensäuren. Aus diesem Grunde ist es verständlich, daß die in der Literatur angegebenen Normalwerte für Gallensäuren im Serum zwischen 0 und $50 \mathrm{mg} \%$ schwanken.

In jüngster Zeit ist eine Arbeit von B. Frosch (6) erschienen, in der die konjugierten Gallensäuren nach Abtrennung der Eiweiße mit Äthanol und Extraktion 
der Lipide mit Äther/Heptan dünnschichtchromatographisch bestimmt werden. Dabei lassen sich die Gallensäuren individuell und quantitativ erfassen. Bei dieser Methode werden jedoch nur die in konjugierter Form vorliegenden Gallensäuren bestimmt; die freien Gallensäuren gehen bei der Extraktion der Lipide teilweise verloren. In einer weiteren Arbeit beschreibt FrosCr die Bestimmung der freien Gallensäuren nach Hydrolyse (7). - Eine andere Möglichkeit wurde kürzlich von japanischen Autoren (8) mitgeteilt, die die Gallensäuren enzymatisch im optischen Test bestimmten. - Schließlich ist noch die Gaschromatographie als spezifische und exakte Bestimmungsmethode zu erwähnen. SJövall (9) hat sich intensiv mit diesem Verfahren beschäftigt, kommt aber auf sehr niedrige Normalwerte, die möglicherweise aut Verluste bei der vorangehenden säulenchromatographischen Reinigung zurückzuführen sind.

Eine Methode für die Bestimmung der Gallensäuren sollte dann genaue Resultate liefern, wenn folgende Bedingungen erfüllt werden können:

1. Extraktion der Gallensäuren mit Äthanol (6).

2. Präparative dünnschichtchromatographische Abtrennung der Lipide mit nachfolgender Elution der Gallensäuren.

Im folgenden wird eine Methode beschrieben, bei welcher diese Bedingungen eingehalten sind. Anstelle der photometrischen quantitativen Auswertung, bei welcher auch nach präparativer Dünnschichtchromatographie noch Störsubstanzen interferieren, werden die Konzentrationen nach der Methode der eben noch sichtbaren Grenzkonzentration (10) auf der Dünnschichtplatte ermittelt. Diese Methode kann auf die Bestimmung der Gallensäuren im Duodenalsaft und Stuhl ausgedehnt werden.

\section{Methodik}

Geräte

Ausrüstung zur Dünnschichtchromatographie der Firma C. Desaga, Heidelberg; Breitbandpipette der Firma Desaga mit 0,1 m/ Inhalt. Homogenisatoren der Firma Polymetron AG., Zürich-Glattbrugg; (Polytron $10 \mathrm{St}$. für Testseren: Polytron $35 \mathrm{St}$. für Stuhl).

\section{Ionenaustauscher-Kolonnen}

Kolonne 1: Kationenaustauscher Dowex $50 \mathrm{~W}-\mathrm{x} 8$; 50-100 mesh in $\mathrm{H}^{+}$-Form. Länge der Säule etwa $30-40 \mathrm{~cm}$; Innerer Durchmesser 1,3 cm; Harzhöhe $16 \mathrm{~cm}$.

Kolonne 2: Anionenaustauscher Dowex $1-x 2 ; 50-100$ mesh in OH--Form. Länge der Säule etwa $30-40 \mathrm{~cm}$; Innerer Durchmesser 1,6 cm; Harzhöhe $13 \mathrm{~cm}$.

Beide Kolonnen werden vor der Verwendung mit $100 \mathrm{ml} 80$ proz. Äthylalkohol gewaschen. Gasblasen entfernt man durch nochmaliges Waschen mit 80 proz. Äthylalkohol.

\section{Chemikalien}

Zur Extraktion der Gallensäuren: Äthanol abs. der Eidgenössischen Alkoholverwaltung ( $\mathrm{Ph}$. H. V.).

Zur Cbromatograpbie: Kieselgel G für Dünnschichtchromatographie, Merck Nr. 7731 ; Eisessig p. a., Merck Nr. 60; n-Butanol, Merck Nr. 988; Toluol, Merck Nr. 98325; Methanol, Merck Nr. 6009; Chloroform, Merck Nr. 2445; Ammoniumcarbonat, Merck Nr. 1135.

\section{Reagenzien}

Spriibreagenz: 10 proz. alkoholische Lösung von Phosphormolybdänsäure, Merck Nr. 532.

Puffer: $\mathrm{P}_{\mathrm{H}}=7$, 3. Gemisch aus $\mathrm{NaH}_{2} \mathrm{PO}_{4}$, Merck Nr. 6343, und $\mathrm{Na}_{2} \mathrm{H} \mathrm{PO}_{4}$, Merck Nr. 6580 (1:4).

Zubereitung der Sorptionsschicht: Die Herstellung der DC-Platten erfolgte in der üblichen Weise mit Kieselgel $G$ nach STAHL. Die Platten wurden aber luftgetrocknet und offen aufbewahrt (11).

Herstellung von Testsubstanzen: Von den Testsubstanzen können nur Cholsäure und Desoxycholsäure in genügender Reinheit käuflich erworben werden. Die Konjugate wurden von uns teils selbst synthetisiert, teils von $H$. DANIELssoN ${ }^{1}$, Karolinska Institutet, Stockholm, freundlicherweise zur Verfügung gestellt. Unsere Synthese erfolgte nach einer Vorschrift von BERGSTRÖM und Norman (12), die auf der Methode der gemischten Anhydride mit Chlorameisensäure-Äthylester und Triäthylamin basiert. Wir reinigten die jeweiligen Rohprodukte durch präparative Dünnschichtchromatographie.

Herstellung der Testseren: Einem Mischserum wird jeweils soviel in einem Puffer gelöste Gallensäure zugeführt, daß man Konzentrationen von 1,5, 3 und $6 \mathrm{mg} \%$ an Cholsäure, Desoxycholsäure, Glykncholsäure, Glykodesoxycholsäure, Taurocholsäure und Taurodesoxychholsäure erhält (Mischen mit Homogenisator). Der Eigengehalt des Serums an Gallensäuren wird in Abzug gebracht.

\section{A rbeitsvorschrift \\ Extraktion der Gallensäuren}

aus dem Serum

$2,5 \mathrm{~m} l$ Serum werden unter Erwärmen in $25 \mathrm{ml}$ Äthylalkohol eingetropft. Im siedenden Wasserbad erhitzt man 3 Min. und filtriert. Der Eiweißniederschlag wird zweimal mit $25 \mathrm{~m} l$ bzw. $10 \mathrm{~m} l$ Äthanol gewaschen. Die vereinigten Filtrate werden im Vakuum zur Trockene eingedampft.

\section{aus dem Duodenalsaft}

$1 \mathrm{~m} l$ Duodenalsaft wird mit $50 \mathrm{ml}$ Äthylalkohol unter Erwärmen extrahiert, filtriert und eingedampft. Man. nimmt nun in $0,5 \mathrm{~m} l$ Äthylalkohol auf und verfährt weiter wie beim Serum.

aus dem Stubl und Ionenaustauscber-Vorreinigung des Stubls's) $100 \mathrm{~g}$ Stuhl werden in ein bei $750 \mathrm{~m} l$ kalibriertes Gefäß abgewogen. Zunächst gibt man etwa $100 \mathrm{~m} l 96$ proz. Äthylalkohol zu. Der Stuhl wird mit einem hochtourigen Rührer (Homogenisator) 5 Min. gerührt. Man läßt auf Zimmertemperatur abkühlen und füllt dann mit 96 proz. Äthylalkohol auf $750 \mathrm{~m} l$ auf, wobei gleichzeitig die Wandungen des Gefäßes und der Rührer abgespült werden. Man rührt nun nochmals $10 \mathrm{Min}$., läßt anschließend die Festbestandteile absitzen und entnimmt einen aliquoten Teil von $50 \mathrm{~m} l$ des klaren Úberstandes zur weiteren Verarbeitung.

Der alkoholische Extrakt $(50 \mathrm{~m} /)$ wird in Kolonne 1 eingefüllt. Der Ausfluß dieser Kolonne wird mit Kolonne 2 verbunden. Man spült nun das Eluat der Kolonne 1 mit $50 \mathrm{~m} / 80$ proz. Äthylalkohol in Kolonne 2. Nach

1) Der Autor dankt Herrn Doz. H. Danielsson für die Uberlassung der Proben.

2) Den Herren Gunther W. Kuron und David M. Tennent, Merck Institute for Therapeutic Research, Rahway, New Jersey, sei für die Uberlassung dieses Teiles der Arbeitsvorschrift bestens gedankt. 
diesem Schritt wird Kolonne 1 auf die Seite gestellt. Kolonne 2 wird der Reihe nach mit folgenden Lösungen gewaschen:
1. $25 \mathrm{~m} / 50$ proz. Alkohol
2. $25 \mathrm{~m} / \mathrm{CO}_{2}$-freies $\mathrm{H}_{2} \mathrm{O}$ (gekocht)
3. $50 \mathrm{~m} / \mathrm{H}_{2} \mathrm{O}$
4. $100 \mathrm{~m} /$ wäßriges $1 \mathrm{~m} \mathrm{NaCl}$
5. $100 \mathrm{ml}$ wäßriges $0,5 \mathrm{~m}\left(\mathrm{NH}_{4}\right)_{2} \mathrm{CO}_{3}$
6. $\mathrm{H}_{2} \mathrm{O}$ zur neutralen Reaktion
7. $25 \mathrm{ml} \mathrm{CO}_{2}$-freies $\mathrm{H}_{2} \mathrm{O}$ (gekocht)
8. $50 \mathrm{~m} / 50$ proz. Alkohol

Die Gallensäuren werden von Kolonne 2 mit $250 \mathrm{ml}$ $0,1 \mathrm{~m}\left(\mathrm{NH}_{4}\right)_{2} \mathrm{CO}_{3}$ in 50 proz. Äthylalkohol quantitativ eluiert. Die $250 \mathrm{~m} l$ Eluat aus Kolonne 2 werden am Rotationsverdampfer zur Trockene verdampft und am Vakuum solange auf einer Temperatur von $100^{\circ}$ gehalten, bis alles Ammoniumkarbonat entwichen ist. Man nimmt nun in $0,5 \mathrm{ml}$ Äthylalkohol auf, trägt diese Lösung zu gleichen Teilen (je $0,25 \mathrm{~m} l$ ) auf zwei Dünnschichtplatten auf und verfährt weiter wie beim Serum.

\section{Präparative diinnschichtcbromatographische Vorreinigung der} Extrakte aus Serum, Duodenalsaft und Stubl

Der trockene Extrakt aus Serum, Duodenalsaft oder Stuhl wird in $0,5 \mathrm{ml}$ Äthanol aufgenommen. Die Lösung wird je zur Hälfte mit einer Breitbandpipette auf 2 Kieselgel-Platten aufgetragen.

Zur Bestimmung der freien Gallensäuren wird die eine der beiden Platten in einer Dünnschichtkammer im System Toluol/Eisessig/Wasser $(7: 7: 1)$ chromatographiert (Steighöhe $10 \mathrm{~cm}$ ). Nach dem Trocknen der Platte im Wärmeschrank besprüht man diese zur Sichtbarmachung der Gallensäurefront mit dest. Wasser, wobei die Grenze zwischen den Fettsäureestern und dem Cholesterin einerseits und den polareren Gallensäuren andererseits deutlich festgestellt und mit einem Strich markiert werden kann ( $6 \mathrm{~cm}$ vom Start). Nach erneutem Trocknen der Platte im Wärmeschrank wird das unterhalb der Markierung befindliche Kieselgel mit einer Rasierklinge abgetragen, mit zweimal $5 \mathrm{ml}$ Äthylalkohol extrahiert und filtriert. Die Filtrate werden vereinigt und am Vakuum zur Trockene eingedampft. Zur Bestimmung der Konjugate entwickelt man die zweite Dünnschichtplatte im System Chloroform/Methanol/Wasser (24:7: 1) (Steighöhe $10 \mathrm{~cm}$ ). Nach der
Entwicklung wird die Schicht bis zu einer Höhe von $2,5 \mathrm{~cm}$ vom Startpunkt an gerechnet, abgetragen. Wie oben werden nach zweimaligem Extrahieren mit $5 \mathrm{ml}$ Äthylalkohol die vereinigten Filtrate zur Trockene eingedampft.

Die semiquantitative Bestimmung der Gallensäuren nach präparativer dïnnscbicbtcbromatographischer Vorreinigung

Unter leichtem Erwärmen löst man die trockenen Rückstände in je $0,25 \mathrm{ml}$ Äthylalkohol. Von dieser Lösung werden auf zwei Platten je 5, 10, 20, 40, 60 und $80 \mu l$ aufgetragen und für die freien Gallensäuren im System Toluol/Eisessig/Wasser $(7: 7: 1)$ und für die Konjugate im System Butanol/Eisessig/Wasser $(10: 1: 1)$ entwickelt. Nach dem Trocknen besprüht man die Platten mit Phosphormolybdänsäure-Reagenz und erwärmt während $10 \mathrm{Min}$. bei $100^{\circ}$ im Trockenschrank. Es läßt sich leicht feststellen, bei welcher Auftragsmenge der Gallensäurefleck erstmals sichtbar wird. Um die zur jeweiligen kleinsten sichtbaren Menge gehörige Gallensäurekonzentration zu errechnen, benötigt man Vergleichszahlen einer Testreihe der entsprechenden Gallensäuren (s. oben). Mit diesen Seren bekannter Gallensäurekonzentrationen wird genauso verfahren, wie es oben für die unbekannten Seren beschrieben wurde. Auch hier wird die kleinste gerade noch sichtbare Menge ermittelt. - Man erhält die in Tabelle 1 aufgeführten Werte.

Bei den verwendeten Systemen konnten die beiden Dihydroxysäuren, Desoxycholsäure und Chenodesoxycholsäure nicht getrennt werden. Mit der Angabe von Desoxycholsäure, bzw. deren Konjugaten, ist daher immer die entsprechende Chenodesoxycholsäure miterfaßt.

\section{Ergebnisse}

Die Resultate der Untersuchungen von Duodenalsaft und Stuhl werden in einer späteren Arbeit mitgeteilt. In Tabelle 2 geben wir die Ergebnisse der Bestimmung der Gallensäuren im Serum ${ }^{1}$ ) von 20 klinisch gesunden Erwachsenen an.

1) Herrn Dr. med. Metaxas, Leiter des Blutspendezentrums des Schweiz. Roten Kreuzes in Zürich, sei an dieser Stelle für die Uberlassung der Seren bestens gedankt.

Tab. 1

\begin{tabular}{lrrrrrr}
\hline $\begin{array}{c}\text { Serum-Konzentrations-Test } \\
\text { in mg\% }\end{array}$ & C & DC & \multicolumn{2}{c}{ Kleinste sichtbare Menge in $\mu l$} \\
TC & TDC & GC & GDC \\
\hline (Serum-Leerwert) $*)$ & 80 & neg. & neg. & neg. & neg. & neg. \\
1,5 & 20 & 20 & 20 & 20 & 80 & 80 \\
3 & 10 & 10 & 10 & 10 & 20 & 20 \\
6 & 5 & 5 & 5 & 5 & 10 & 10 \\
\hline
\end{tabular}

*) Als Leerwert wurde ein Serụm mit geringem Gallensäuregehalt verwendet.

$\begin{array}{lll}\text { Abkïrzungen: } & \mathrm{C}=\text { Cholsäure } & \text { GDC = Glykodesoxycholsäure } \\ & \text { DC = Desoxycholsäure } & \text { CDC = Chenodesoxycholsäure } \\ \text { TC }=\text { Taurocholsäure } & \text { GCDC = Glykochenodesoxycholsäure } \\ & \text { TDC = Taurodesoxycholsäure } & \text { TCDC = Taurochenodesoxycholsäurc } \\ & \text { GC }=\text { Glykocholsäure } & \end{array}$


Tab. 2

Konzentration der Serum-Gallensäuren in $\mathrm{mg} \%$ (Erläuterungen siehe Tab. 1). Werte unter $0,1 \mathrm{mg} \%$ konnten nicht mehr erfaßt werden.

\begin{tabular}{|c|c|c|c|c|c|c|c|}
\hline \multirow[b]{2}{*}{ Geschlecht } & \multirow[b]{2}{*}{ Serum Nr. } & \multicolumn{2}{|c|}{ Freie Gallensäure } & \multirow[b]{2}{*}{ TC } & \multicolumn{2}{|c|}{ Konjugierte Gallensäure } & \multirow[b]{2}{*}{$\begin{array}{r}\text { GDC } \\
+\mathrm{GCDC}\end{array}$} \\
\hline & & $\mathrm{C}^{-2}$ & $\begin{array}{c}\mathrm{DC} \\
+\mathrm{CDC}\end{array}$ & & $\begin{aligned} & \text { TDC } \\
+ & \text { TCDC }\end{aligned}$ & GC & \\
\hline q & 1 & 1.5 & $<0.1$ & $<0.1$ & $<0.1$ & 0.75 & 0.25 \\
\hline 字 & 2 & 0.75 & $<0.1$ & $<0.1$ & $<0.1$ & 0.75 & 0.37 \\
\hline$\stackrel{+}{+}$ & 3 & 0.75 & $<0.1$ & $<0.1$ & $<0.1$ & $<0.1$ & $<0.1$ \\
\hline + & 4 & 0.75 & 0.30 & $<0.1$ & $<0.1$ & 0.50 & 0.25 \\
\hline 字 & 5 & 0.75 & $<0.1$ & $<0.1$ & $<0.1$ & $<0.1$ & $<0.1$ \\
\hline o & 6 & 0.25 & $<0.1$ & $<0.1$ & 0.15 & $<0.1$ & $<0.1$ \\
\hline 오 & 7 & 0.75 & $<0.1$ & 0.75 & $<0.1$ & 0.35 & $<0.1$ \\
\hline 우 & 8 & 0.50 & $<0.1$ & 0.15 & $<0.1$ & 0.75 & $<0.1$ \\
\hline ơ & 9 & 0.25 & $<0.1$ & 0.15 & 0.25 & 0.37 & $<0.1$ \\
\hline$q_{+}^{+}$ & 10 & 0.37 & $<0.1$ & 0.15 & $<0.1$ & $<0.1$ & $<0.1$ \\
\hline$\sigma$ & 11 & 0.75 & 0.30 & $<0.1$ & $<0.1$ & $<0.1$ & $<0.1$ \\
\hline 0 & 12 & 0.75 & 0.25 & $<0.1$ & $<0.1$ & $<0.1$ & $<0.1$ \\
\hline$\hat{\sigma}$ & 13 & 0.37 & $<0.1$ & 0.25 & 0.25 & $<0.1$ & $<0.1$ \\
\hline$\sigma$ & 14 & 0.75 & 0.25 & 0.25 & $<0.1$ & $<0.1$ & $<0.1$ \\
\hline 0 & 15 & 0.75 & 0.18 & $<0.1$ & $<0.1$ & $<0.1$ & $<0.1$ \\
\hline 0 & 16 & 0.25 & 0.37 & 0.15 & $<0.1$ & $<0.1$ & $<0.1$ \\
\hline i & 17 & 0.75 & 0.37 & $<0.1$ & $<0.1$ & 0.25 & $<0.1$ \\
\hline a & 18 & 0.75 & $<0.1$ & 0.15 & $<0.1$ & $<0.1$ & $<0.1$ \\
\hline$\sigma$ & 19 & 0.37 & $<0.1$ & 0.25 & $<0.1$ & 0.37 & $<0.1$ \\
\hline 0 & 20 & 0.75 & $<0.1$ & 0.25 & $<0.1$ & $<0.1$ & $<0.1$ \\
\hline
\end{tabular}

Aus Tabelle 2 geht hervor, daß die Cholsäure in ihrer freien Form die höchste Konzentration aufweist, während sie als Taurin- oder Glycin-Konjugat bei ungefähr der Hälfte der Fälle unter der Nachweisgrenze liegt. Bei Frauen läßt sich mehr Glykocholsäure nachweisen als bei Männern. Die Konzentration an Cholsäure und Taurocholsäure ist bei Frauen und Männern ungefähr gleich. Desoxycholsäure (Chenodesoxycholsäure) zeigt bei Frauen und Männern keinen ins Auge fallenden Konzentrationsunterschied. Taurodesoxycholsäure (Taurochenodesoxycholsäure) sowie Glykodesoxycholsäure (Glykochenodesoxycholsäure) liegen fast durchweg unter der Nachweisgrenze von $0,1 \mathrm{mg} \%$.

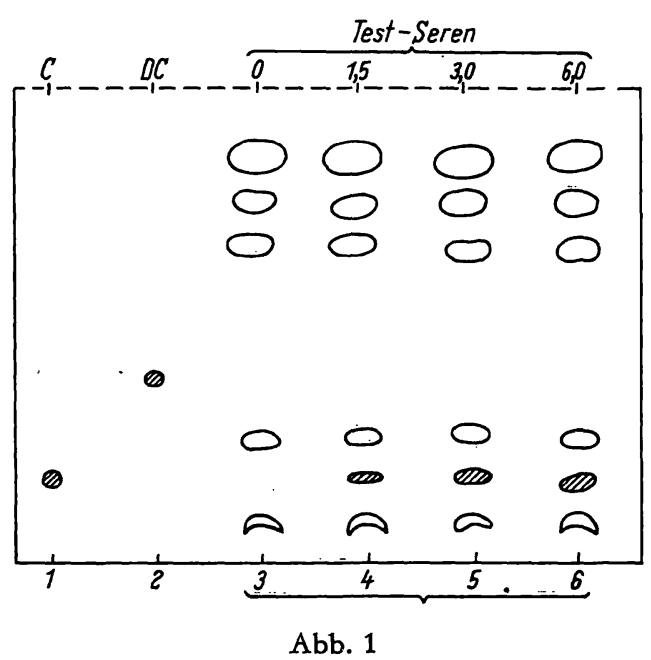

Dünnschichtchromatographische Trennung freier Serumgallensäuren in Toluol-Eisessig-Wasser $7: 7: 1$

$1=$ Cholsäure $\quad 4=$ Zumischung von $1,5 \mathrm{mg} \%$ Cholsäure

$2=$ Desoxycholsäure $5=$ Zumischung von $3,0 \mathrm{mg} \%$ Cholsäure

3 = Serumleerwert $\quad 6=$ Zumischung von $6,0 \mathrm{mg} \%$ Cholsäure

\section{Diskussion}

Die routinemäßig durchführbare quantitative Erfassung der Gesamtgallensäuren sowie der einzelnen Komponenten in freier oder konjugierter Form ist bisher infolge der umständlichen Methodik auf Schwierigkeiten gestoßen. Bei vielen Verfahren ist der Verlust an Gallensäuren während der Extraktion zu groß. Die hier beschriebene Methode eliminiert diese Nachteile weitgehend. - Bei dem häufig angewendeten Verfahren nach JosEpHSON (1) werden durch Verseifung der Lipide mit Barytwasser/Bariumacetat im Reaktionsgemisch * Fettsäuren freigesetzt und als Bariumsalze wasserlöslich gemacht. Diese können durch Ausschütteln nicht mehr

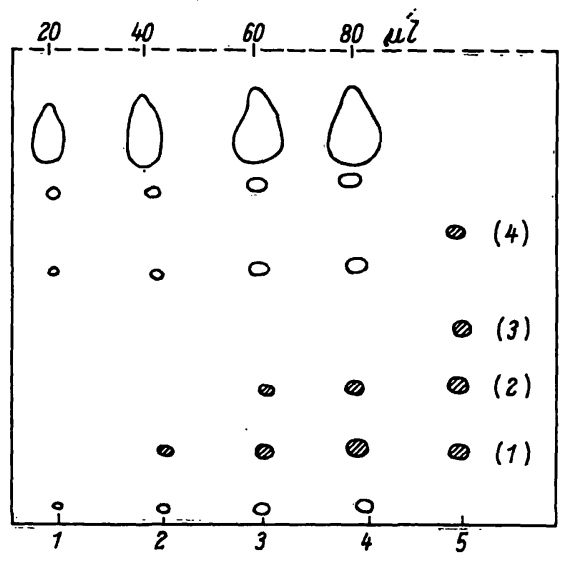

Abb. 2

Dünnschichtchromatographischè Trennung konjugierter Serumgallensäuren in Butanol-Eisessig-Wasser 10:1:1

(1) $=$ Taurocholsäure

(2) = Taurodesoxycholsäure (Taurochenodesoxycholsäure)

(3) = Glykocholsäure

(4) = Glykodesoxycholsäure (Glykochenodesoxycholsäure)

$1-4=20-80 \mu l$ gereinigte Serumextrakte ohne Zumischung $5=$ Testmischung 
von der wässerigen Phase getrennt werden. - Wird zur Fällung der Eiweiße lediglich Äthanol verwendet, so ist dieser Nachteil ausgeschaltet. Verluste an Gallensäuren treten ferner auf bei der anschließenden Extraktion in einem unpolaren organischen Lösungsmittel. Dieser Arbeitsgang ist in der hier beschriebenen Methode durch die präparative dünnschichtchromatographische Vorreinigung der äthanolischen Lösung ersetzt.

In der vorliegenden Methodik werden die Testsubstanzen einem Mischserum zugesetzt und durch den gesamten Analysengang mitgeführt (Tab. 1). Dies hat den Vorteil, daß die Verluste während des Arbeitsprozesses bei der Berechnung der Konzentration der Gallensäuren in den Seren (Tab. 2) von vornherein miteinbezogen sind. - Mit der Methode können Werte von über $0,1 \mathrm{mg} \%$ semiquantitativ bestimmt werden.
Die Werte für die konjugierten Gallensäuren liegen in mehr als der Hälfte der Bestimmungen unter der Nachweisgrenze von $0,1 \mathrm{mg} \%$. Damit ist eine weitgehende Ubereinstimmung mit den von Frosch $(6,7)$ mitgeteilten Werten erreicht. Bei den freien Gallensäuren, vor allem der Cholsäure, wurden in der vorliegenden Arbeit im Vergleich zu Frosch etwas höhere Konzentrationen nachgewiesen. Die Werte für die freie Cholsäure liegen in den hier untersuchten Fällen deutlich über denjenigen der beiden Dihydroxysäuren (DC $+\mathrm{CDC}$ ) sowie der konjugierten Gallensäuren.

Ich danke der Firma Merck Sharp und Dohme, Rahway (New Jersey) und den Herren Dr. U. P. Hämmerl.I und Dr. J. Müller von der Medizinischen Universitätsklinik Zürich, durch deren großzügiges Entgegenkommen die vorliegende Arbeit ermöglicht wurde.

\title{
Literatur
}

1. Josephon, B., Biochem. J. 29, 1519 (1935). - 2. Kier, L. C., J.Laborat. Clin. Med., S. Louis, 40, 755 (1952). - 3. Levin, S. J. und $C_{\text {H. }}$ G. Johnston, J. Laborat. Clin. Med., S. Louis, 59, 681 (1962). - 4. Lirvin, J., C. G. Johnston und J. Kopala, J. biol. Chemistry 153, 439 (1944). - 5. MrNiBECK, H., Biochem. Z. 297, 29, 40 und 214 (1938). - 6. Frosch, B., Arzneimittel Forsch. 15, 178 (1965). - 7. Frosch, B., Klin. Wschr. 43, 262 (1965). - 8. Tsuyoshr, I. und K. Yamasak,; J. Biochemistry (Tokyo) 56, 5
(1964). - 9. Sandberg, D., K. Sjövall und D. A. Turner, Federat. Proc. 22, 198 (1963). - 10. Patakr, G., Dünnschichtchramotographie in der Aminosäure- und Peptidchemie. (Im Druck), De Gruyter u. Co., Berlin. - 11. BrenNer, M., A. Niederwieser, G. Pataki und A. R. Fahmy, Experientia (Basel) 18, 101 (1962). - 12. Bergström, S. und A. Norman, Acta chem. scand. 7,1126 (1953).

\section{Zur Abhängigkeit der Bestimmung der ,wahren Glucose“ von der Glas-Sorte der Reagenzgläser ${ }^{1)}$}

\author{
Von W. Forth und K. Pfleger \\ Aus dem Pharmakologischen Institut der Universität des Saarlandes, Homburg/Saar (Direktor: Prof. Dr. W. Rum mel)
}

(Eingegangen am 11. Mai 1965)

\begin{abstract}
Eine systematische Prüfung der von Frank und Kirberger modifizierten Methode zur Bestimmung der ,wahren Glucose" nach NeLson zeigt, daß es nicht gleichgültig ist, in welcher Glas-Sorte die Oxydation der zu messenden Glucose bzw. die stöchiometrische Reduktion des Kupfers stattfindet. Bei der Bestimmung von Glucose in Lösungen, deren Konzentration 30-60 mg\% betrug, werden in Fiolax-Gläsern z. B. nur 20-30\% der Einwaage erfaßt. In Duran- bzw. Pyrex-Glas macht sich diese Störung nicht bemerkbar. Wahrscheinlich ist die Störung auf den Arsen-Gehalt des Fiolax-Glases zurückzuführen.

The systematical control of the method of NeLson for the estimation of glucose modified by Frank. and KIrberger showed, that it is not indifferent in which kind of glass the oxidation of glucose or the stechiometrical reduction of copper is carried out. The determination of glucose in a concentration of $30-60 \mathrm{mg} \%$ in Fiolax test tubes yields only $20-30 \%$ of the total amount whereas in Duran i. e. Pyrex test tubes a $100 \%$ yield is achieved. It is most likely that the interference of Fiolax glass with the method depends on arsenic found in this glass.
\end{abstract}

Nach Einführung einer neuen Reagenzglas-Sorte in unserem Institut (1960), in dem bis dahin ausschließlich Pyrex-Glas französischer Herkunft verwendet wurde, machten häufiger auftretende Störungen die Überprüfung der von Frank und KIRBERGER modifizierten Methode zur Glucose-Bestimmung nach NELSON nötig

1) Uber einen Teil der Ergebnisse wurde auf der gemeinsamen Tagung der Deutschen Gesellschaft für Physiologische Chemie und der Osterreichischen Biochemischen Gesellschaft in Wien (26.-29. 9. 1962) berichtet.
(2). Dabei fiel auf, daß regelmäßig in bestimmten Reagenzgläsern aus Fiolax-Glas die Werte der GlucoseBestimmung in ein und derselben Lösung erheblich niedriger ausfielen als in Pyrex-Gläsern, die wir mit den neuen Reagenzgläsern zunächst wahllos vermischt benutzten. Die Störungen der Glucose-Bestimmung in Fiolax-Glas waren besonders bei der Messung niedriger Glucose-Konzentrationen ausgeprägt, d. h. in einem Konzentrations-Bereich, der - auf die Blutzuckerbestimmung übertragen - klinisch gerade besonders 